\title{
A novel fibrinogen gamma-chain mutation, p. yAla327Val, causes structural abnormality of $D$ region and ultimately leads to congenital dysfibrinogenemia
}

\author{
Aiqiu Wei ${ }^{1 \#}$, Yangyang Wu ${ }^{1 \#}$, Liqun Xiang${ }^{1}$, Jie Yan ${ }^{1}$, Peng Cheng², Donghong \\ Deng ${ }^{2 *}$, Faquan Lin ${ }^{1 *}$
}

${ }^{1}$ Department of Clinical Laboratory, The First Affiliated Hospital of Guangxi Medical University, Nanning, Guangxi, China

${ }^{2}$ Department of Hematology, The First Affiliated Hospital of Guangxi Medical University, Nanning, Guangxi, China

\#Aiqiu Wei and Yangyang $\mathrm{Wu}$ contributed equally to this work and are co-first authors.

*Corresponding authors: Faquan Lin, Department of Clinical Laboratory, The First Affiliated Hospital of Guangxi Medical University, Nanning, Guangxi, China. Email: fqlin1998@163.com. Donghong Deng, Department of Hematology, The First Affiliated Hospital of Guangxi Medical University, Nanning, Guangxi, China. Email: ddh_gx@163.com.

KEYWORDS Congenital dysfibrinogenemia; Fibrinogen; Gene mutation; Molecular mechanism

Thromboelastography
ABSTRACT
fibrinogen gene, which result in abnormal
Congenital
dysfibrinogenemia
(CD) is a
fibrinogen function. Many studies have confirmed 
asymptomatic. In this study, we aimed to investigate the pathogenesis of CD caused by $\gamma$ Ala327Val heterozygous mutation, a new mutation, by studying fibrinogen function. Blood samples of patients were collected and the coagulation function, fibrinogen (Fg) aggregation test, fibrin clot lysis test, and SDS-PAGE were performed. Coagulation was monitored using a thromboelastometer, and the fibrin clot network structure was observed by scanning electron microscopy. The eff ect of the mutation on fibrinogen structure and function was predicted by molecular modeling. The fibrinogen activity concentration in patients with $\mathrm{CD}$ was significantly lower than that in healthy individuals. Thromboelastography showed that the $\mathrm{K}$ value of patients with $\mathrm{CD}$ was higher than that for healthy individuals. The Angle values were also decreased. The function of fibrinogen in patients with $\mathrm{CD}$ was low. Compared to fibrinogen from healthy individuals, fibrin size was different, the fiber network structure was loose, the pore size was increased, and the fiber branch nodes were increased for fibrinogen isolated from the proband. The $\gamma$ Ala327Val mutation led to changes in the structure of fibrinogen D region, affecting its structural stability. Ala327Val heterozygous missense mutation in exon 8 of FGG gene $\gamma$-chain thus leads to abnormal fibrinogen structure and impairs the aggregation function of fibrinogen.
This mutation is reported here for the first time.

\section{Introduction}

Fibrinogen (Fg), also known as coagulation factor $\mathrm{I}$, is mainly produced by liver cells and is secreted into peripheral blood. Its plasma concentration is 2-4 g/L [1]. Fibrinogen is involved in the formation of fibrin clots and platelet aggregation, and plays an important role in hemostasis. At the initial stage of fibrin clot formation, fibrinogen binds to platelet membrane protein IIb/IIIa, activates platelets, and mediates platelet aggregation, thus participating in the coagulation process. The relative molecular weight of fibrinogen is $340 \mathrm{kD}$; it is composed of two identical subunits, each of which comprises three different polypeptide chains (A $\alpha, \mathrm{B} \beta$, and $\gamma$ ); these two subunits are linked by disulfide bonds [2]. Fibrinogen molecules have three major functional regions, the central region (E region) and two symmetric distal spherical $\mathrm{D}$ regions (Figure 1). The three polypeptide chains A $\alpha, B \beta$, and $\gamma$ are encoded by FGA, FGB, and FGG genes (on chromosome 4), respectively [3].

Mutations in FGA, FGB, or FGG may lead to the development of congenital dysfibrinogenemia (CD). CD is a congenital blood disease caused by 


\section{Novel fibrinogen mutation and congenital dysfibrinogenemia}

defects in fibrinogen genes, which lead to abnormal structure and function of fibrinogen molecules, and may affect coagulation. The clinical manifestations of $\mathrm{CD}$ are diverse; most patients with CD are asymptomatic [4], but a small number of patients with $\mathrm{CD}$ have thrombosis $[5,6]$ and bleeding events, and some patients have pulmonary hypertension and other symptoms [7]. As most patients with CD are asymptomatic, and the single detection method used currently in clinical laboratories may lead to misdiagnosis or missed diagnosis, the incidence of $\mathrm{CD}$ is thus difficult to determine at present.

In this study, we identified a novel heterozygous mutation (FGG c.1058C > T, $\gamma$ Ala327Val) in an asymptomatic patient with abnormal fibrinogenemia. Functional studies of fibrinogen isolated from the patient and her family members were performed to study the molecular pathogenesis of $\mathrm{CD}$ caused by $\gamma$ Ala327Val heterozygous missense mutation.

\section{Methods}

Basic data of patients and routine examination of coagulation function

The proband was a 45-year-old female patient. When she came to the hospital for physical examination, her coagulation function test result was abnormal: fibrinogen activity concentration was $0.75 \mathrm{~g} / \mathrm{L}$ (Clauss method) and antigen concentration (immune turbidimetry method) was $1.59 \mathrm{~g} / \mathrm{L}$ (normal reference range for both parameters: $\quad 2.0-4.0 \mathrm{~g} / \mathrm{L})$. Fibrinogen activity concentration was significantly lower than fibrinogen antigen concentration. Liver function, kidney function, and blood routine tests were normal, and there were no bleeding or thrombotic events in daily life. Four members of her family were examined for coagulation function and other parameters.

DNA was extracted from the peripheral blood samples of the proband and four members of her family. DNA sequencing was performed by Beijing Liuhe Huada Gene Technology Co., Ltd, Beijing, China.

\section{Fibrinogen aggregation test}

Venous blood $(5 \mathrm{ml}$, in sodium citrate anticoagulant) was drawn from the patients and healthy controls, and centrifuged at $4^{\circ} \mathrm{C}, 3000 \mathrm{rpm}$, for $15 \mathrm{~min}$ to separate the plasma. Then, $1 \mathrm{ml}$ sodium citrate $(0.09 \mathrm{~mol} / \mathrm{L})$ and $666 \mu \mathrm{l}$ saturated ammonium sulfate $(\mathrm{pH} 5.5)$ were added to $1 \mathrm{ml}$ plasma, and the mixture was incubated at $25^{\circ} \mathrm{C}$ for 70 minutes. After centrifugation, the supernatant was discarded and fibrinogen was obtained. The reaction system of the fibrinogen aggregation test was as follows: Fibrinogen $0.5 \mathrm{mg} / \mathrm{ml}$ (final concentration), $5 \mathrm{ml}$ of $2 \mathrm{~mol} / \mathrm{L} \mathrm{NaCl}, 5 \mathrm{ml}$ of 2 
$\mathrm{mmol} / \mathrm{L} \mathrm{CaCl}$, and $20 \mathrm{mmol} / \mathrm{L}$ HEPES buffer to make the volume up to $90 \mathrm{ml}$. Then, $10 \mathrm{U} / \mathrm{ml}$ of 10 $\mu \mathrm{l}$ thrombin was added and the optical density (OD) of the sample at $365 \mathrm{~nm}$ was continuously monitored (one reading every 20 seconds for 30 minutes) using a multimode plate reader Multiskan Go (ThermoFischer). The aggregation curve was drawn according to the time and the corresponding OD value.

\section{Fibrin clot dissolution test}

Fibrin clot dissolution test was performed by adding fibrinolytic enzyme and tPA into the fibrinogen aggregation test system to activate fibrin clot dissolution, and we continuously measured the OD value of the reaction system to reflect the rate of fibrin clot dissolution. The reaction system used for this test was as follows:

The final concentrations of fibrinogen, thrombin, plasminogen, tPA, $\mathrm{CaCl}_{2}$, and $\mathrm{NaCl}$ were 0.5 $\mathrm{mg} / \mathrm{ml}, 0.5 \mathrm{U} / \mathrm{ml}, 0.12 \mathrm{U} / \mathrm{ml}, 0.1 \mathrm{mg} / \mathrm{ml}, 8 \mathrm{mmol} / \mathrm{L}$, $0.12 \mathrm{mmol} / \mathrm{L}$, and $20 \mathrm{mmol} / \mathrm{L}$, respectively. Finally, $20 \mathrm{mmol} / \mathrm{L}$ HEPES was used to make up the volume of the reaction system to $200 \mathrm{ml}$. The OD values of the samples at $365 \mathrm{~nm}$ were continuously monitored with Multiskan Go (ThermoFisher, USA) for 30 minutes at $20 \mathrm{~s}$ intervals. The fibrin clot dissolution curve was drawn according to the time and the corresponding OD value.
Whole blood samples $(1 \mathrm{ml})$ from the study subjects were added to the reagent bottle (Shaanxi Yuze Yi Medical Technology Co., Ltd Shaanxi, China); Then, $340 \mu \mathrm{l}$ of the sample with $20 \mu \mathrm{l}$ of $0.2 \mathrm{~mol} / \mathrm{L} \mathrm{CaCl}_{2}$ was added into the detection cup of the thromboelastography (TEG) instrument (Shaanxi Yuze Yi Medical Technology Co., Ltd, Shaanxi, China). As fibrinogen began to aggregate, the probe placed in the detection cup was subjected to shear stress produced during the formation and dissolution of the blood clot. The generated signal was transmitted to the processor in the form of a current and a TEG curve was obtained.

\section{$S D S-P A G E$}

Fibrinogen was mixed with loading buffer (containing $\beta$-mercaptoethanol) and the mixture was heated for $5 \mathrm{~min}$ at $100^{\circ} \mathrm{C}$. Sodium dodecyl sulfate polyacrylamide gel electrophoresis (SDS-PAGE) was performed on $10 \%$ gels using the BioRad Mini-Protean Tetra Electrophoresis System (Bio-Rad, CA, USA). The gel was stained with Coomassie brilliant blue R-250 and was scanned on a gel imager ( Bio-Rad Laboratories (Shanghai) Co., Ltd. ) .

\section{Scanning electron microscopy}

The proband and healthy individuals were administered $33 \mu \mathrm{l}$ of fibrinogen each, and thrombin was added at a final concentration of 2

\section{Thromboelastography}


$\mathrm{U} / \mathrm{ml})$. After incubation for 3 hours at $37^{\circ} \mathrm{C}$, the samples from proband and healthy individuals were rinsed with PBS buffer ( $\mathrm{pH} 7.4,0.1 \mathrm{~mol} / \mathrm{L})$, and incubated with 3\% glutaraldehyde for 2 hours. Glutaraldehyde was discarded, samples were rinsed with PBS solution, and dehydrated with alcohol. The ultrastructure of the fibrin clot was observed with VEGA3LMU scanning electron microscope (TESCAN, Czech Republic).

\section{Modeling and analysis of amino acid mutation}

The amino acid sequence of fibrinogen was obtained from the NCBI database, and a model of the fibrinogen structure was constructed using

\section{SWISS-MODEL} website

\section{(https://swissmodel.expasy.org/)/.}

Swiss-Pdb

Viewer software was used to analyze the effect of $\gamma$ Ala327Val mutation on the function of fibrinogen.

\section{Results}

\section{Routine coagulation function tests}

The Results of the laboratory examination for the proband including electrolyte, liver and kidney function, and blood routine tests were normal. Examination of these parameters for other members of the family showed that the coagulation results of the proband's sister, two brothers, and proband's daughter were similar to those of the proband, and there were no abnormalities in the results of the electrolyte, liver and kidney function, and blood routine tests. There were no clinical manifestations in daily life. The results of the coagulation function test are given in table 1. A single base heterozygous missense mutation ( $\mathrm{C}$. $1058 \mathrm{C}>\mathrm{T}, \quad \gamma$ Ala327Val) in exon 8 of the fibrinogen gene was found in the proband and her family members (Figure 2).

\section{Fibrinogen aggregation test}

Compared with the healthy individuals, the OD values of fibrinogen aggregation curves for fibrinogen isolated from the proband and her family members were changed slightly, and the maximum OD values from 5 patients (average 0.283) were lower than those of the healthy individual (0.422) (Figure 3).

\section{Fibrin clot dissolution test}

The clot turbidity began to decrease after 496 seconds on average (healthy individuals: after 660 seconds). There was no fibrinolysis delay and resistance during clot dissolution (Figure 4).

\section{Thromboelastography}

The $\mathrm{K}$ values (time when the strength of blood clot reaches $20 \mathrm{~mm}$ ) of patients with $\mathrm{CD}$ were increased; the average value was $3.7 \mathrm{~min}$ for the patients whereas it was $2.3 \mathrm{~min}$ for healthy individuals. Further, the Angle values (the angle between tangent line and horizontal line from the 


\section{Novel fibrinogen mutation and congenital dysfibrinogenemia}

point of clot formation to the maximum curve radian of the figure) were decreased. The average value was $52.8^{\circ}$ for the patients, whereas it was $61.5^{\circ}$ for the healthy individuals. The thromboelastography results are shown in Figure 5 and Table 2.

\section{$S D S-P A G E$}

The SDS-PAGE results revealed that the proband and her family members did not show any variant protein bands (Figure 6).

\section{Ultrastructure of fibrin clot}

Shown in Figure 7 (A) is the structure of the control fibrin clot under a scanning electron microscope. The diameter of the fiber filament was uniform, the fiber nodes were few, the arrangement was neat and compact, the fiber filament interweaved and overlapped to form a fiber network, the spatial structure was relatively dense, and the network pore size was small. (B) The fibrin clot network structure of the proband showed that the fiber filaments were of different thickness, arranged irregularly, and the ends of the fiber filaments were curled into a mass. The fiber network space structure was loose, the network aperture increased, and the fiber branch nodes were more than those in the healthy individual.

\section{Modeling and analysis of amino acid mutations}

In the molecular model of wild-type fibrinogen, $\gamma$
Ala327 is located in the $\alpha$ helix of D domain of the fibrinogen $\gamma$ chain. The $\alpha$ helix is crucial to maintaining protein stability. The $\gamma$ Ala327 backbone and $\gamma$ Ser332 backbone form a hydrogen bond, which is $3.19 \mathrm{~nm}$ long. When Ala is replaced by Val, the hydrogen bond between $\gamma$-Val327 and $\gamma$-Ser332 did not change, but the side chain became longer, which affected its spatial structure, and the electrostatic force around it changed, which led to a change in the structure of the $\alpha$-helix and weakening of protein stability (Figure 8).

\section{Discussion}

Congenital dysfibrinogenemia (CD) is a hereditary blood disease caused by the defects in fibrinogen genes, which leads to the abnormal structure and function of fibrinogen, and may affect coagulation. Fibrinogen genes (FGA, FGB, and FGG) are located on chromosome 4 of the human genome, and mutations in any of them may cause changes in the structure and/or function of fibrinogen. The mutations in fibrinogen gene include missense mutation caused by single base substitution, frameshift mutation caused by single base insertion or deletion, and mutations in the regulatory region. Single base substitution is the most common form of mutation that results in CD. So far, over 450 mutations in fibrinogen gene has been registered (www.geht.org). Single amino acid mutations are 


\section{Novel fibrinogen mutation and congenital dysfibrinogenemia}

reported at 212 sites, of which mutations in FGA gene are the most common followed by mutations in FGG [8]. AaArg16 and $\gamma \operatorname{Arg} 275$ are the most common mutation sites in $\mathrm{CD}$, and most common substitutions are A $\alpha$ Arg16His, A $\alpha$ Arg16Cys, $\gamma \operatorname{Arg} 275 \mathrm{Cys}$ or $\gamma \operatorname{Arg} 275 \mathrm{His}$, which can be used as gene sites to screen for CD. In 101 cases of CD reported, mutations at these two sites accounted for $74 \%$ of the mutations [9].

In this study, the genetic testing results of the proband and her family members revealed a heterozygous missense mutation $(\mathrm{C} .1058 \mathrm{C}>\mathrm{T})$ in exon 8 of the FGG gene, which resulted in Ala to Val substitution at position 327 of the $\gamma$ chain. Structure modeling analysis showed that this change resulted in a spatial position and electrostatic force change, resulting in change in the structure of the $\alpha$-helix and weakening of stability. Although interaction between D:E regions is the main driving force of fibrinogen aggregation, the D:D interaction is also important for fibrin oligomer formation [10-12]. The role of D:D interaction is to guide the $\mathrm{D}$ regions of the two fibrinogen monomers to connect; D:D interaction thus assists $\gamma$ chain polymerization, which is necessary for fibrin end-to-end binding. By projecting the D:D region and analyzing its crystal structure, it was found that the interface of D: D polymerization is composed of hydrogen bonds between two adjacent fibrinogen molecules, and that the D: D interaction is crucial for fibrin monomers to aggregate horizontally and linearly $[10,13]$. The amino acids at position $88-406$ of the gamma chain encoded by FGG gene form the main functional domain of the D region [14], and the mutation site $\gamma$ Ala327 investigated in this study is located in this region. In $\gamma \mathrm{Ala} 327 \mathrm{Val}$, alanine is replaced by valine, which affects the secondary structure, changes spatial arrangement, affects the D:D binding between the gamma chains of fibrinogen, and hinders the formation of fibrils, thereby affecting the aggregation of fibrinogen. Our aggregation test and thromboelastography results revealed that the proband and her family members had impaired fibrin aggregation.

The ultrastructure of the probands' fibrin clots was observed by scanning electron microscopy. The sizes of the filaments were different, the arrangement was irregular, the ends of the filaments were coiled, the fiber network was loose, the aperture of the network was enlarged, and there were many fiber nodes. Defects in the D:D interaction between adjacent fibrinogen molecules leads to easy lateral extension of the filament, resulting in an increase in branch points and formation of thinner filaments [15]. Substitution of $\gamma$ Ala327 results in incorrect end-to-end location of fibrin monomers during aggregation, resulting in 


\section{Novel fibrinogen mutation and congenital dysfibrinogenemia}

the increase in fiber branching. Further, during polymerization, normal fibrin monomers can combine with mutant monomers, resulting in inconsistent fiber diameter, irregular arrangement, looseness, and large mesh-like structure. Analysis of the mutant fibrin clot network showed that the fibrin clots with impaired D:D interaction ( $\gamma$ Arg275His, $\gamma$ Arg275Cys and $\gamma$ Arg375Gly) had more pores in the network structure, and that the network comprised many conical fibers and pores [16]. These results are similar to those of this study. Sugo et al [14] suggested that the structure of fibrin clot might be related to the clinical phenotype, and the phenotype could be predicted by studying the ultrastructure and network structure of fibrin clot. Studies have shown that the dissolution rate of fibrin clot depends on the density of its structure rather than the diameter of fibrin fibers, and the loose fibrin network structure composed of crude fibers is easier to be decomposed than the dense fibrin network structure composed of fine fibers [17]. Patients with high fibrin density in the fibrin network have a higher risk of thrombotic events [18].

In patients with thrombotic $\mathrm{CD}$, such as fibrinogen Paris V [19] (FGAc.1717C > T) and fibrinogen Perth [20] (FGAc.1541delC), fibrinolytic time is prolonged. In this study, fibrinolysis prolongation and fibrinolysis resistance were not found in patients with $\mathrm{CD}$ when compared with healthy individuals, suggesting that $\gamma$ Ala327Val mutation does not affect fibrin clot dissolution.

The concentration of fibrinogen antigen detected by immunoturbidimetry was normal in patients with $\mathrm{CD}$, but the concentration of fibrinogen activity detected by Clauss method was significantly decreased. Immunoturbidimetry is based on the specific binding of fibrinogen antibody to fibrinogen. As fibrinogen antigen determinants are present in mutant fibrinogen molecules, the concentration of fibrinogen antigen in plasma of patients with CD will not be reduced. Combination of multiple methods to detect fibrinogen can reduce the rate of misdiagnosis and missed diagnosis of CD. Our previous study showed that the combination of PT-derived method and Clauss method is helpful to screen CD [21]. In this study, in the proband, the concentration of fibrinogen activity was significantly lower than that of fibrinogen antigen $(0.75 \mathrm{~g} / \mathrm{L}$ vs $1.59 \mathrm{~g} / \mathrm{L}$, reference range: 2-4 g/L). Liver and kidney function, electrolyte, and blood routine examinations were not abnormal, excluding secondary factors. Gene sequencing found $\gamma$ Ala327Val mutation, which could be used to diagnose the proband as having CD. Through fibrinogen aggregation test, fibrin clot dissolution test, and thromboelastography, the function of 
fibrinogen was analyzed, and the defect of fibrinogen aggregation function was found. The ultrastructure of fibrin network was observed by electron microscopy, and the changes in fibrinogen structure caused by the mutation were studied. It was found that the branches of fibrin network increased, and the arrangement was irregular, loose and the mesh was large. These changes may affect the process of fibrin aggregation. Although no bleeding or thrombotic events have occurred in this family, the possibility that thrombotic or hemorrhagic events will occur in the future, especially in the case of surgery, postpartum, or trauma, cannot be excluded. Long-term follow-up studies of patients with $\mathrm{CD}$ have shown that patients without clinical symptoms at diagnosis may still have thrombotic or bleeding events several years later, and that their risk of bleeding or thrombosis is relatively high [9]. Barbara et al [22] reported a case of $\mathrm{CD}$ with an $\alpha$ Arg16His homozygous mutation (fibrinogen Giessen I), who had no bleeding or thrombotic events in daily life, but had symptoms of massive bleeding during delivery. Therefore, the proband and her family still need follow-up observation to prevent thrombosis or bleeding and other events.

\section{Acknowledgments}

We would like to thank the Department of Hematology and Clinical Laboratory of the First
Affiliated Hospital of Guangxi Medical University, China. This research was supported by Grants from the National Natural Science Foundation of China (81560342).

\section{Conflict of interest}

None.

\section{Author contributions}

The authors declare that they have no conflict of interest with the content of this article.

\section{References}

1 Tennent GA, Brennan SO, Stangou AJ, John OG, Hawkins PN, Pepys MB. Human plasma fibrinogen is synthesized in the liver. Blood. 2007; 109: 1971-4.

\section{Medved L, Weisel JW. Recommendations for} nomenclature on fibrinogen and fibrin. Journal of Thrombosis \& Haemostasis. 2010; 7: 355-9.

3 Zhou J, Ding Q, Chen Y, Ouyang Q, Jiang L, Dai J, Lu Y, Wu X, Liang Q, Wang H, Wang X. Clinical features and molecular basis of 102 Chinese patients with congenital dysfibrinogenemia. Blood Cells $\mathrm{Mol}$ Dis. 2015; 55: 308-15. 10.1016/j.bcmd.2015.06.002.

4 Yan J, Deng D, Luo M, Cheng P, Chi B, Yuan Y, Liao L, Lin F. Dysfibrinogenemia in a patient undergoing artificial abortion after misdiagnosis and review of the literature. Clin Chim Acta. 2015; 447:

86-9. 10.1016/j.cca.2015.06.002.

5 Luo M, Wei A, Xiang L, Yan J, Liao L, Deng X, Deng $D$, Cheng $P$, Lin F. Abnormal fibrinogen with an Aalpha 16Arg --> Cys substitution is associated with multiple cerebral infarctions. J Thromb Thrombolysis. 2018; 46: 409-19. 10.1007/s11239-018-1689-z.

6 Hamano A, Mimuro J, Aoshima M, Itoh T, Kitamura N, Nishinarita S, Takano K, Ishiwata A, Kashiwakura Y, Niwa K. Thrombophilic dysfibrinogen 
Tokyo $\mathrm{V}$ with the amino acid substitution of gammaAla327Thr: formation of fragile but fibrinolysis-resistant fibrin clots and its relevance to arterial thromboembolism. Blood. 2004; 103: 3045-50.

7 Casini A, Neerman-Arbez M, Ariens RA, de Moerloose P. Dysfibrinogenemia: from molecular anomalies to clinical manifestations and management. J Thromb Haemost. 2015; 13: 909-19. 10.1111/jth.12916.

8 Neerman-Arbez M, de Moerloose P, Casini A. Laboratory and Genetic Investigation of Mutations Accounting for Congenital Fibrinogen Disorders. Semin Thromb Hemost. 2016; 42: 356-65. 10.1055/s-0036-1571340.

9 Casini A, Blondon M, Lebreton A, Koegel J, Tintillier V, de Maistre E, Gautier P, Biron C, Neerman-Arbez M, de Moerloose P. Natural history of patients with congenital dysfibrinogenemia. Blood. 2015; 125: 553-61. 10.1182/blood-2014-06-582866.

10 Everse SJ, Spraggon G, Veerapandian L, Riley M, Doolittle RF. Crystal structure of fragment double-D from human fibrin with two different bound ligands. Biochemistry. 1998; 37: 8637-42.

10.1021/bi9804129.

11 Weisel JW, Warren SG, Cohen C. Crystals of modified fibrinogen: size, shape and packing of molecules. J Mol Biol. 1978; 126: 159-83.

12 Zhmurov A, Brown AE, Litvinov RI, Dima RI, Weisel JW, Barsegov V. Mechanism of fibrin(ogen) forced unfolding. Structure. 2011; 19: 1615-24. 10.1016/j.str.2011.08.013.

13 Ishikawa S, Hirota-Kawadobora M, Tozuka M, Ishii K, Terasawa F, Okumura N. Recombinant fibrinogen, gamma275Arg-->Cys, exhibits formation of disulfide bond with cysteine and severely impaired D:D interactions. J Thromb Haemost. 2004; 2: 468-75.
14 Xu P, Wng M, Xie H, et al. A novel point mutation (Asp316His) in $\gamma$ chain of fibrinogen found in one patient with hypofibrinogenemia [J]. Journal Of Wenzhoumedical University. 2011;41(4):346-8.

15 Cote HC, Lord ST, Pratt KP. gamma-Chain dysfibrinogenemias: molecular structure-function relationships of naturally occurring mutations in the gamma chain of human fibrinogen. Blood. 1998; 92 : 2195-212.

16 Sugo $T$, Endo $H$, Matsuda $M$, Ohmori $T$,

Madoiwa S, Mimuro J, Sakata Y. A classification of the fibrin network structures formed from the hereditary dysfibrinogens. J Thromb Haemost. 2006; 4: 1738-46. 10.1111/j.1538-7836.2006.02043.x.

17 Collet JP, Park D, Lesty C, Soria J, Soria C, Montalescot G, Weisel JW. Influence of fibrin network conformation and fibrin fiber diameter on fibrinolysis speed: dynamic and structural approaches by confocal microscopy. Arterioscler Thromb Vasc Biol. 2000; 20: 1354-61.

18 Undas A, Ariens RA. Fibrin clot structure and function: a role in the pathophysiology of arterial and venous thromboembolic diseases. Arterioscler Thromb Vasc Biol. 2011; 31: e88-99.

10.1161/ATVBAHA.111.230631.

19 Collet JP, Soria J, Mirshahi M, Hirsch M, Dagonnet FB, Caen J, Soria C. Dusart syndrome: a new concept of the relationship between fibrin clot architecture and fibrin clot degradability: hypofibrinolysis related to an abnormal clot structure. Blood. 1993; 82: 2462-9.

20 Westbury SK, Duval C, Philippou H, Brown R, Lee KR, Murden SL, Phillips E, Reilly-Stitt C, Whalley D, Ariens RA, Mumford AD. Partial deletion of the alphaC-domain in the Fibrinogen Perth variant is associated with thrombosis, increased clot strength and delayed fibrinolysis. Thromb Haemost. 2013; 110: 1135-44. 10.1160/TH13-05-0408. 
21 Xiang L, Luo M, Yan J, Liao L, Zhou W, Deng X,

Deng $D$, Cheng P, Lin F. Combined use of Clauss and prothrombin time-derived methods for determining fibrinogen concentrations: Screening for congenital dysfibrinogenemia. J Clin Lab Anal. 2018; 32: e22322. 10.1002/jcla.22322.

22 Alving BM, Henschen AH. Fibrinogen giessen I: a congenital homozygously expressed dysfibrinogenemia with A alpha 16 Arg----His substitution. Am J Hematol. 1987; 25: 479-82. 
bioRxiv preprint doi: https://doi org/10.1101/2020.0129 925172. this version posted January 30,2020 . The copyright holder for this preprint (which was not certified by peer review) is the author/funder, who has granted bioRxiv a license to display the preprint in perpetuity. It is made available under aCC-BY-NC-ND 4.0 International license.

Novel fibrinogen mutation and congenital dysfibrinogenemia

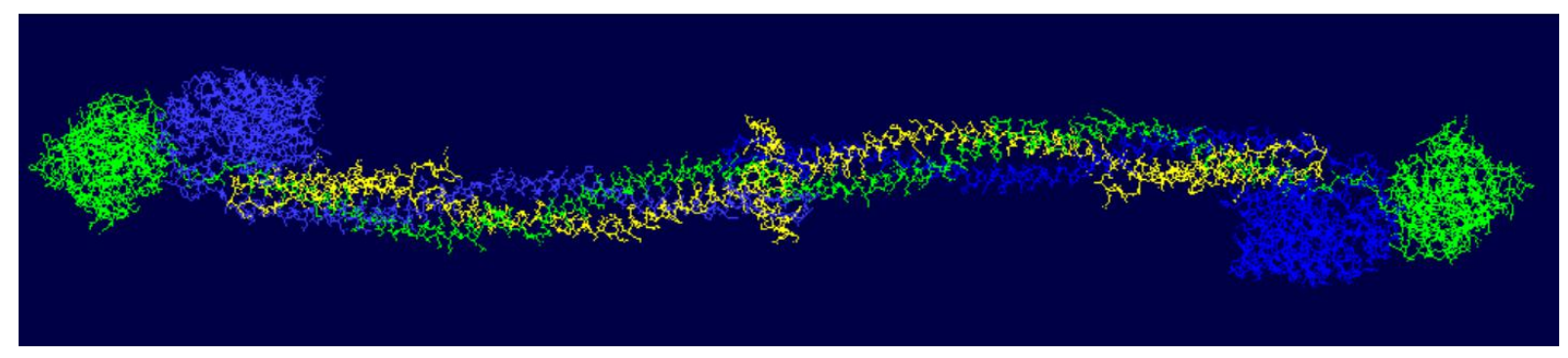

Figure 1. Molecular structure of fibrinogen. 
1

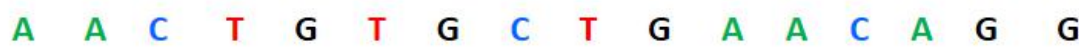

2

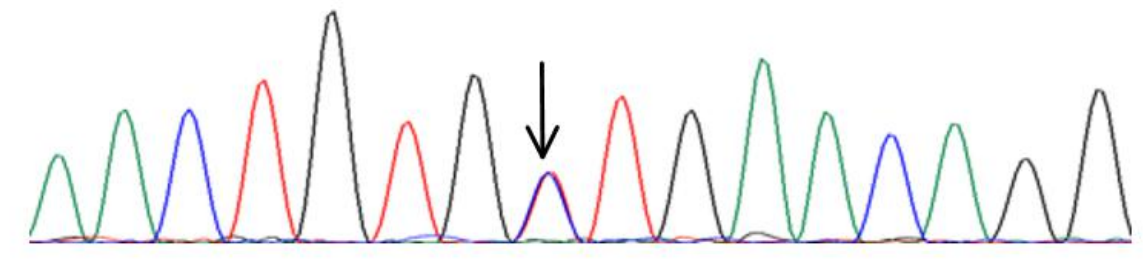

3

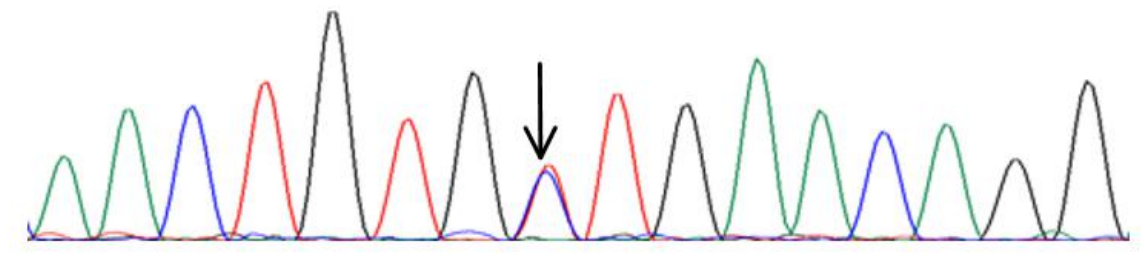

4

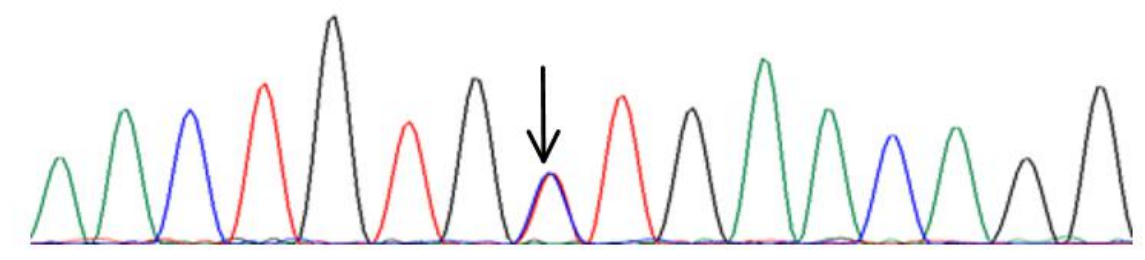

5

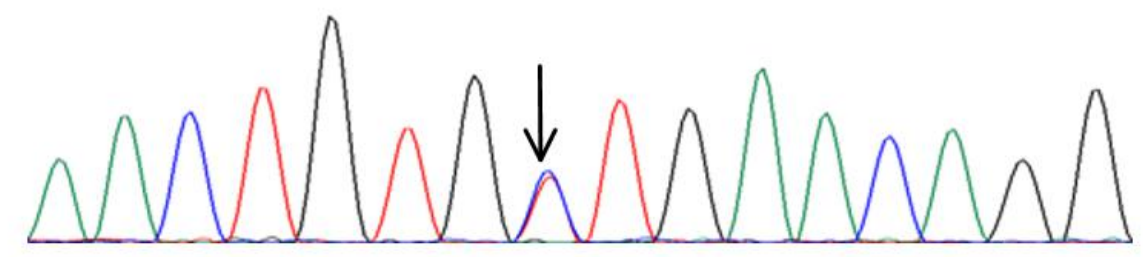

6

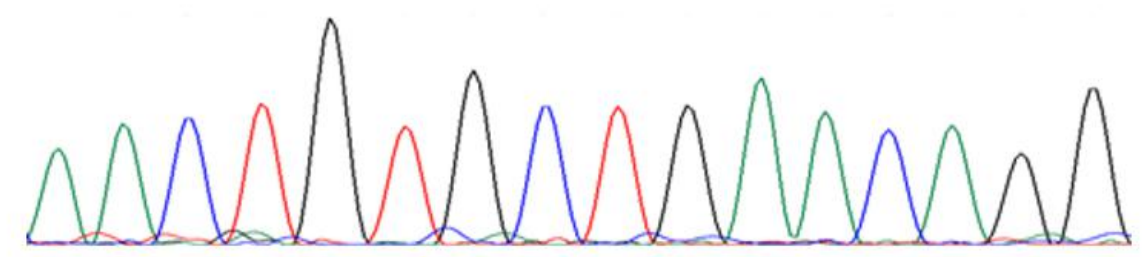

Figure 2. Sequences of gene.1: Proband; 2-5: Proband's family member; 6: Healthy individual ( $\downarrow$ : FGG gene c. $1058 \mathrm{C}>\mathrm{T}$ heterozygous mutation). 
bioRxiv preprint doi: https://doi. org/10.1101/2020.01 29.925172. this version posted January 30, 2020. The copyright holder for this preprint (which was not certified by peer review) is the author/funder, who has granted bioRxiv a license to display the preprint in perpetuity. It is made available under aCC-BY-NC-ND 4.0 International license.

\section{Novel fibrinogen mutation and congenital dysfibrinogenemia}

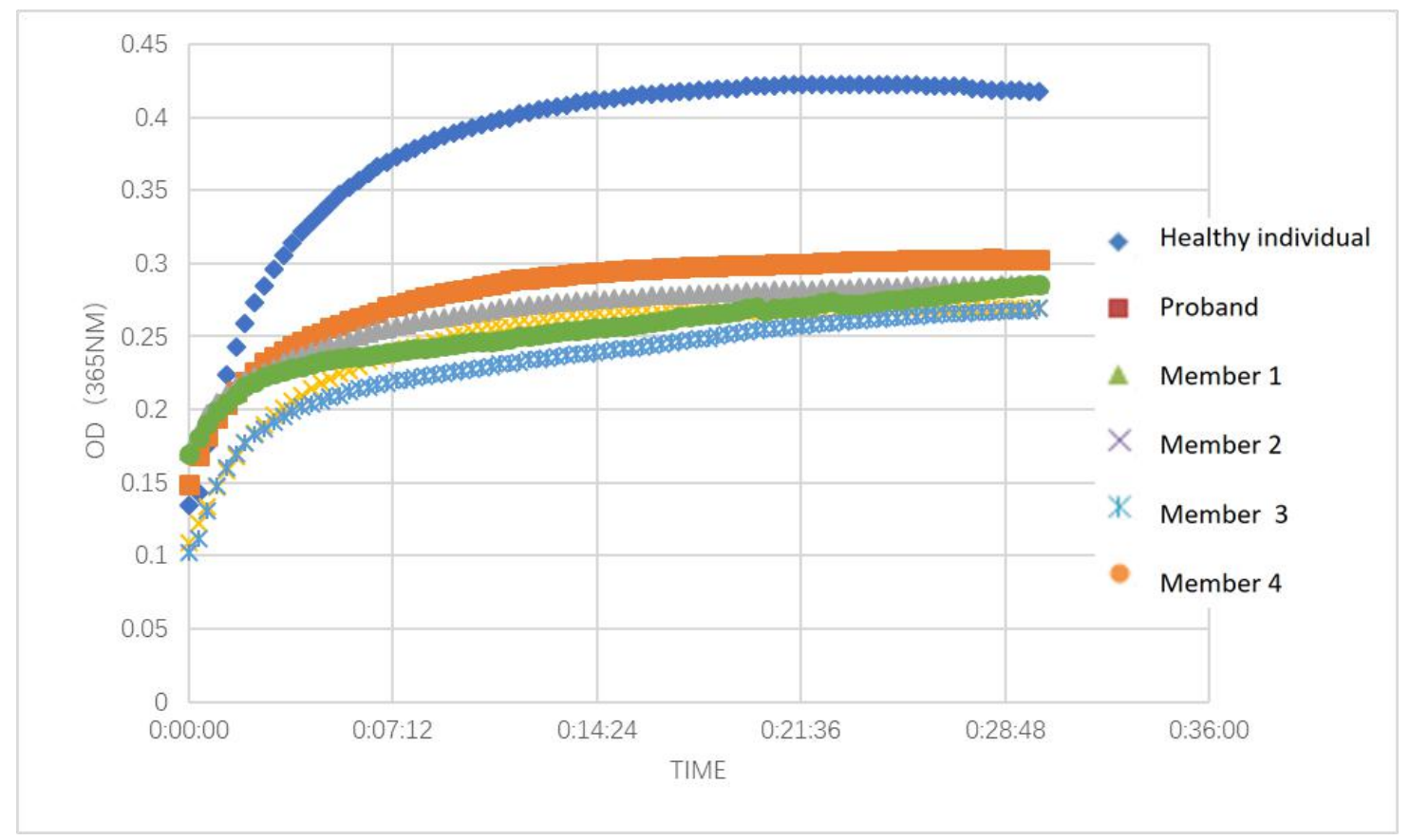

Figure 3. Fibrin polymerization curves.

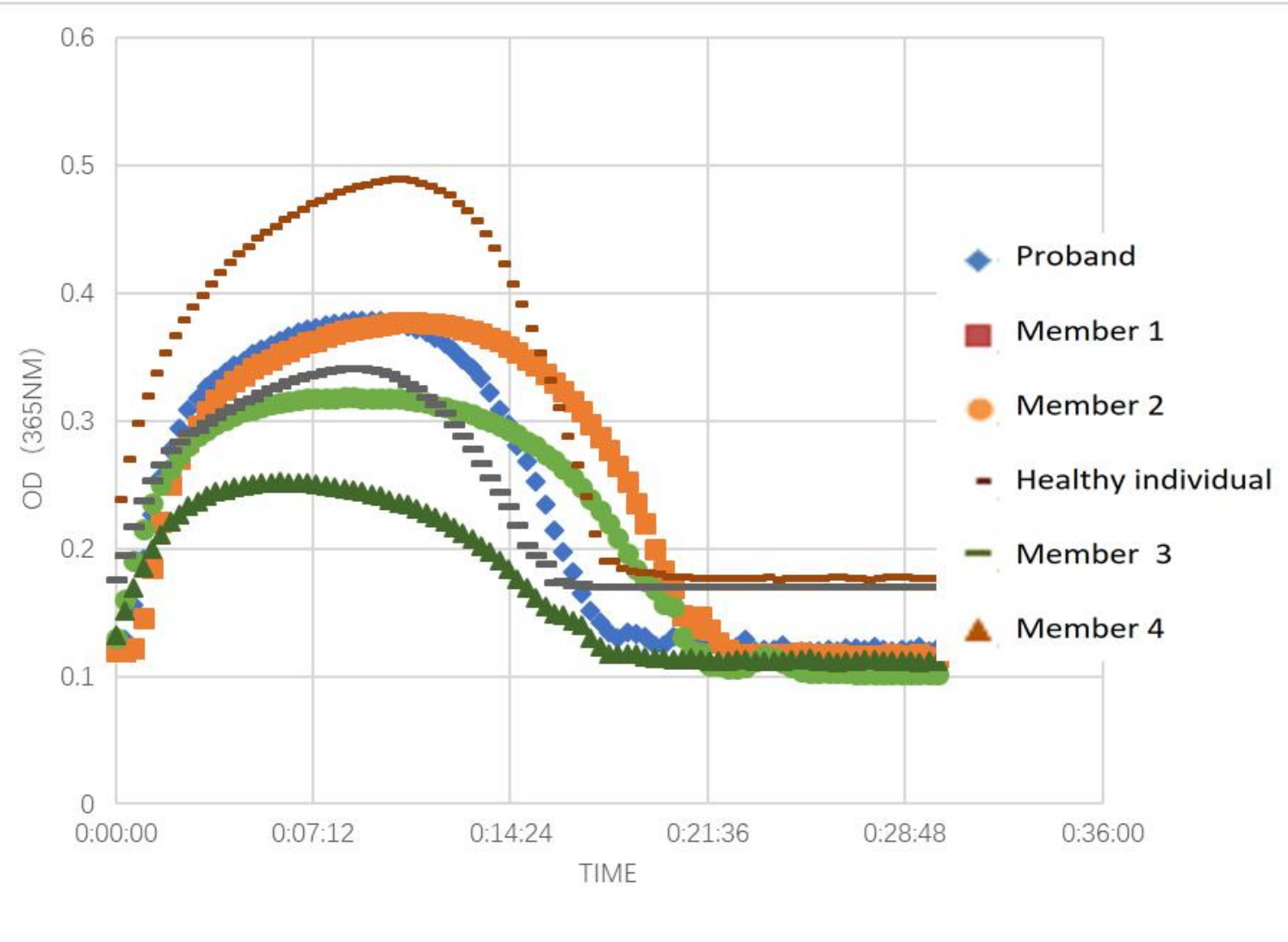

Figure 4. Fibrin clot lysis curves. 
bioRxiv preprint doi: https://doi org/10.1101/2020 0129.925172 . this version posted January 30,2020. The copyright holder for this preprint (which was not certified by peer review) is the author/funder, who has granted bioRxiv a license to display the preprint in perpetuity. It is made available under aCC-BY-NC-ND 4.0 International license.

Novel fibrinogen mutation and congenital dysfibrinogenemia

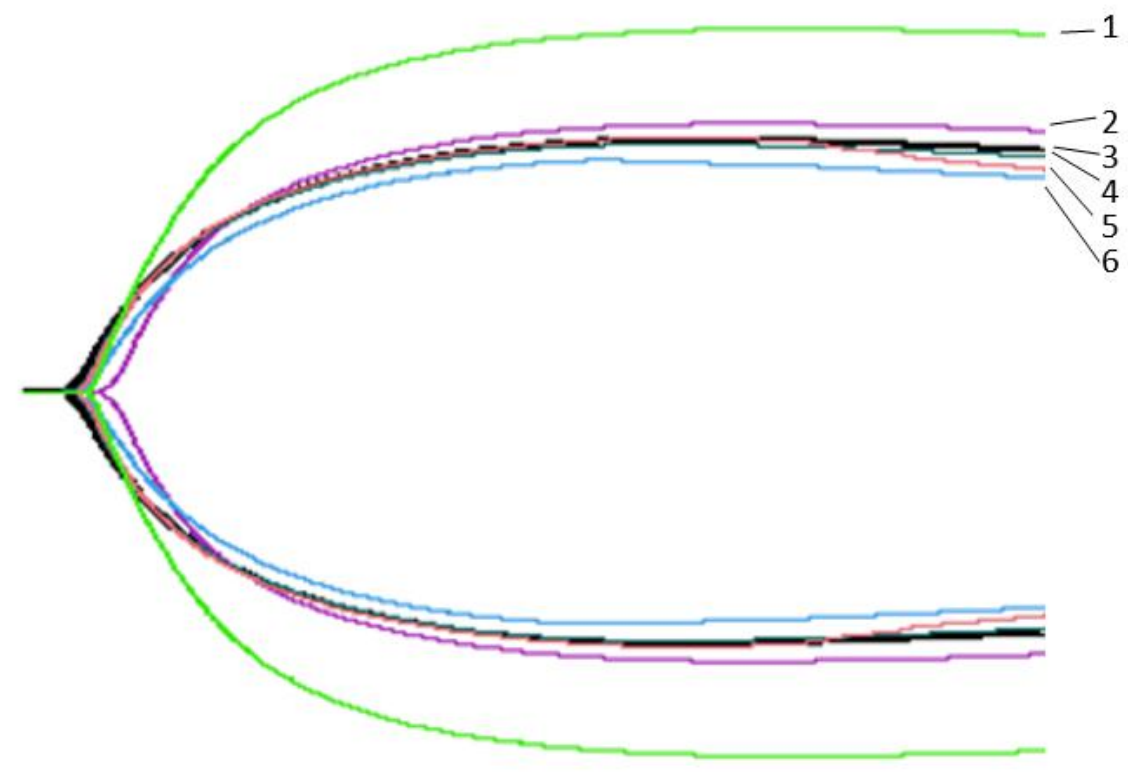

Figure 5. Thromboelastography. 1: Healthy individual; 2-6: Proband and her family members.

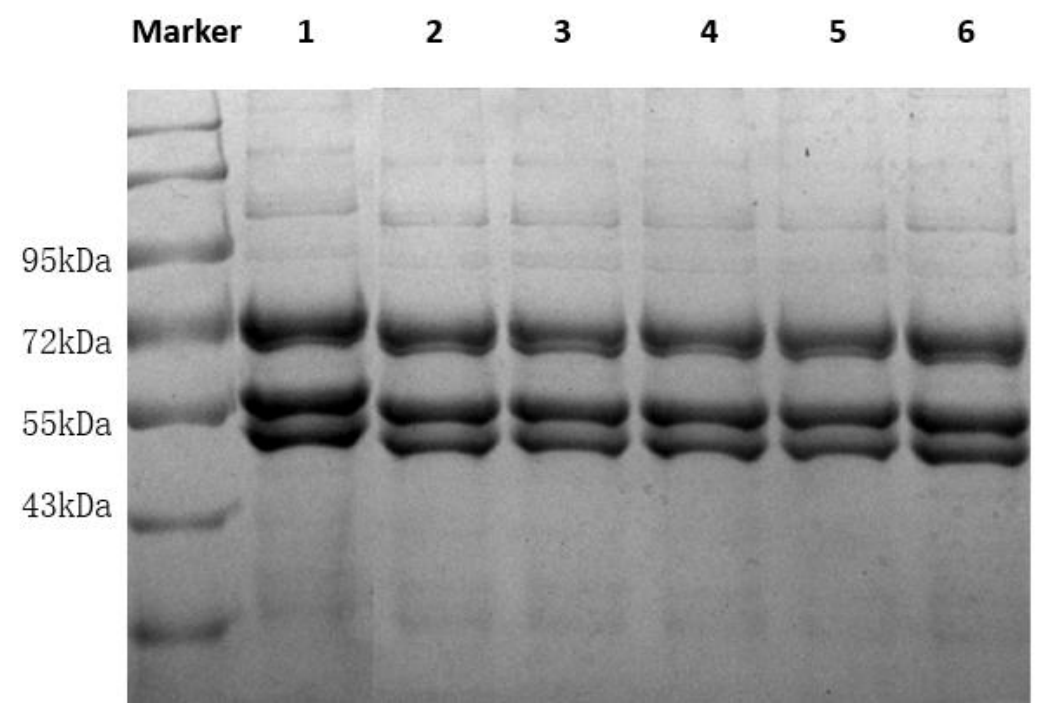

Figure 6. SDS-PAGE of fibrinogen. 1: Healthy individual; 2-6: Proband and her family members. 
bioRxiv preprint doi: https://doi.org/101101/2020 01 29.925172; this version posted January 30,2020 . The copyright holder for this preprint (which was not certified by peer review) is the author/funder, who has granted bioRxiv a license to display the preprint in perpetuity. It is made available under aCC-BY-NC-ND 4.0 International license.

\section{Novel fibrinogen mutation and congenital dysfibrinogenemia}

A

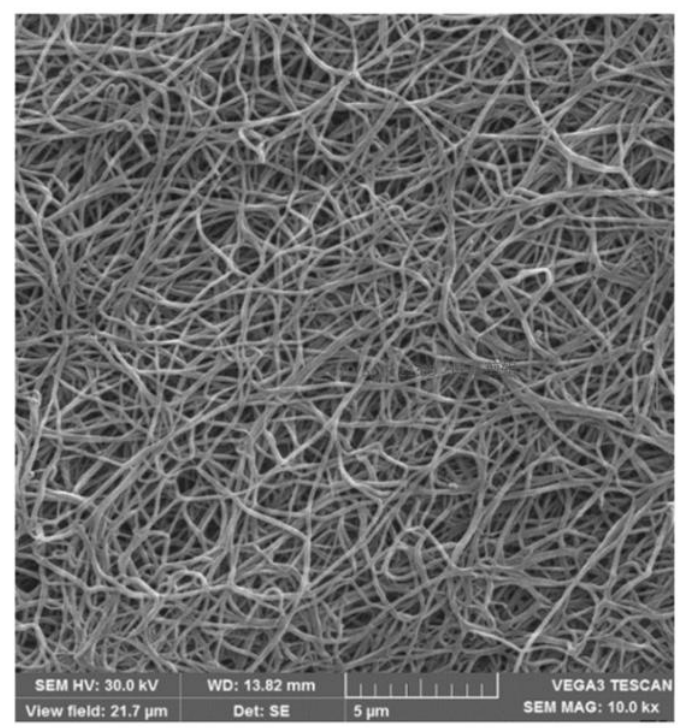

B

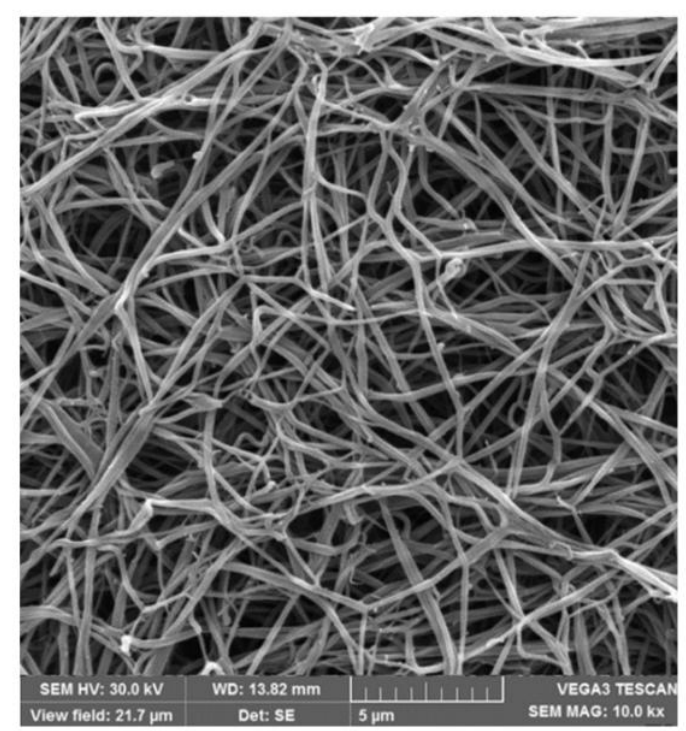

Figure 7. Scanning electron microscopy of fibrin clot. A: Healthy individual; B: Proband.

A

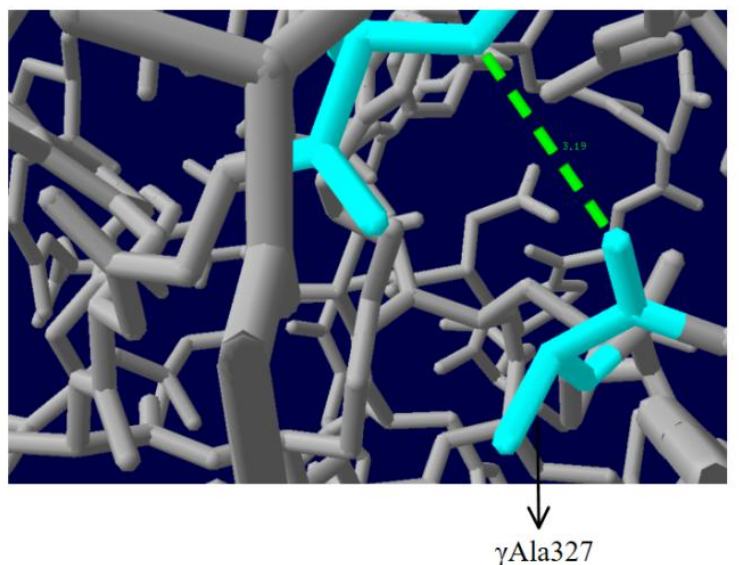

B

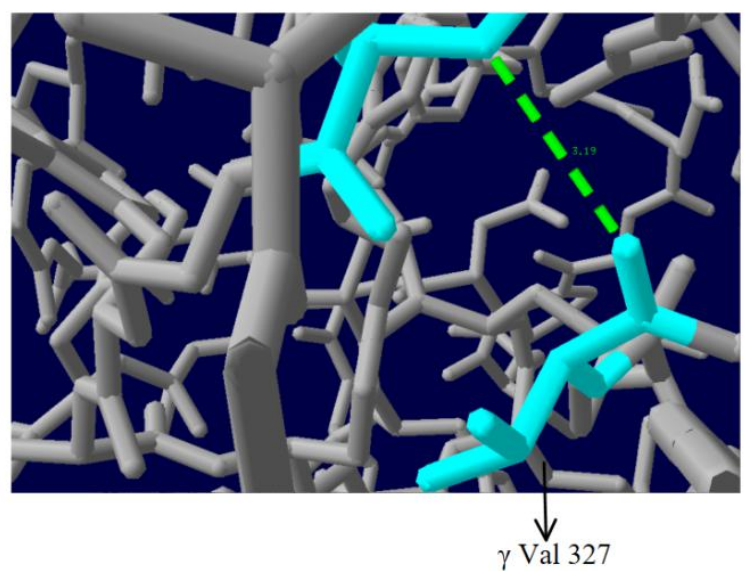

Figure 8. Analysis of the $\gamma$ Ala327Val mutation with protein modelling. A: Healthy individual; B:

Proband. 
Table 1 Coagulation function of proband and her family members.

\begin{tabular}{llllll}
\hline & & \multicolumn{5}{c}{ Fibrinogen $(\mathrm{g} / \mathrm{L})$} \\
Patients & APTT(s) & PT(s) & TT(s) & Clauss method & $\begin{array}{l}\text { immune } \\
\text { method }\end{array}$ \\
& & & & & 1.59 \\
\hline Proband & 27.3 & 12.2 & 15.2 & 0.75 & 2.35 \\
Member 1 & 26.9 & 11.9 & 14.6 & 0.67 & 1.96 \\
Member 2 & 25.2 & 12.5 & 13.5 & 0.74 & 1.92 \\
Member 3 & 26.7 & 12.2 & 15 & 0.67 & 1.57 \\
Member 4 & 35.1 & 13.7 & 16.6 & 0.56 & $2-4$ \\
Reference & $23-40$ & $9-15$ & $9-15$ & $2-4$ & \\
Range & & & & & \\
\hline
\end{tabular}

Table 2 Thromboelastography in the proband, her family members, and healthy individual

\begin{tabular}{llll}
\hline Object & $\mathrm{K}(\mathrm{min})$ & Angle $\left(^{\circ}\right)$ & $\mathrm{CI}$ \\
\hline Healthy individual & 2.3 & 61.5 & 0.9 \\
Proband & 4.1 & 53.1 & -2.0 \\
Member 1 & 3.2 & 52.7 & -2.6 \\
Member 2 & 3.4 & 53.2 & -1.8 \\
Member 3 & 3.5 & 54.3 & -1.8 \\
Member 4 & 4.3 & 50.9 & -3.0 \\
Reference Range & $1-3$ & $53-72$ & $-3-3$ \\
\hline
\end{tabular}

Note: $\mathrm{K}$ value is the time when the strength of blood clot reaches $20 \mathrm{~mm}$; Angle value is the angle between tangent line and horizontal line from the point of clot formation to the maximum curve radian of the figure, CI: comprehensive coagulation index 